\title{
DELINEATING METROPOLITAN AREAS USING LAND PRICES*
}

\author{
Eckhardt Bode \\ Kiel Institute for the World Economy D-24100 Kiel. E-mail: eckhardt.bode@ifw-kiel.de
}

\begin{abstract}
This paper proposes an approach to delineating metropolitan areas that is more general than the standard approaches in three respects: First, it uses the fraction of land prices attributable to economies of urban agglomeration instead of using commuting intensities as an indicator of economic integration between metropolitan centers and their hinterlands. Second, it identifies metropolitan centers endogenously instead of determining them exogenously. And third, it takes metropolitan subcenters explicitly into account. An empirical illustration is used to show that the approach tends to delineate fewer but larger metropolitan areas in densely populated regions, and smaller metropolitan areas in sparsely populated regions.
\end{abstract}

\section{MOTIVATION}

Metropolitan areas play an important role as subjects of regional economic policy, urban planning, and economic analysis in various countries. The metropolitan statistical areas (MSA) in the U.S. or the functional urban regions (FUR) in Western Europe are prominent examples. Metropolitan areas are usually defined as sets of consecutive local administrative areas that comprise at least one larger core city and the adjacent administrative areas that have a high degree of social and economic integration with that core city (e.g., USCB, 2006). In virtually all delineations of metropolitan areas, the commuting intensity between a local administrative area and a core city is used as the indicator for the degree of economic integration. The U.S. MSAs, for example, comprise at least one core city with a population of 50,000 or more as well as any adjacent counties from where at least 25 percent of the employed residents commute to the core city's county (OMB, 2000). Similarly, the Western European FURs comprise at least one core "urbanized area" with 20,000 or more jobs as well as any adjacent NUTS3 regions from where more workers commute to that core than to any other core (Cheshire and Hay, 1989). See Karlsson and Olsson (2006) for a recent survey of the various commuting-based delineation concepts.

*The author would like to thank Frank Bickenbach, Bernard Fingleton, Gilles Duranton, Wilfried Koch, Reinhold Kosfeld, Paul Kramer, Tomoya Mori, Se-il Mun, two anonymous referees, and the participants of the conference on Empirical Methods for the Study of Economic Agglomerations, Kyoto, for helpful discussions and suggestions, Carmen Andersson and Andrea Schäfer for research assistance, and the European Commission financial support.

Received: August 2006; accepted: July 2007. 
Arguing that the commuting intensity indicator is too narrow, the present paper proposes an approach for delineating metropolitan areas that uses, instead of commuting intensities, the fraction of land prices attributable to economies of urban agglomeration as the indicator of the degree of economic integration between a metropolitan center and its hinterland. This economic integration is, in addition to commuting, shaped by a variety of economic interactions and interdependencies that generate agglomeration economies but are unrelated to commuting (e.g., Combes and Overman, 2004; Duranton and Puga, 2004; Duranton, 2006; Rosenthal and Strange, 2004): Households benefit from shopping centers, long-distance transport hubs, or attractive public services available in the metropolitan area. Firms benefit from thick local product and labor markets in their metropolitan area, from having important suppliers, customers, or competitors close by, or from receiving localized knowledge spillovers from other firms in the metropolitan area.

Commuting intensities will, in fact, serve as a reasonable proxy of the intensities of other interactions and interdependencies in delineations of metropolitan areas, if (i) these interactions and interdependencies shape the internal structures of metropolitan areas in the same way as commuting does, and if (ii) they do not extend across significantly higher distances. Theoretical and empirical studies indicate that these two conditions are not met. As to the first condition, it has in fact been shown theoretically that various economies of urban agglomeration shape the internal structure of a metropolitan area in the same way as commuting does, if the metropolitan area is monocentric (Lucas and Rossi-Hansberg, 2002; Abdel-Rahman and Anas, 2004). It has, however, also been shown theoretically that the externalities between firms actually substitute for, rather than complement, commuting, if the metropolitan area is polycentric (Fujita and Thisse, 2002; Lucas and Rossi-Hansberg, 2002; Anas and Xiong, 2005). To benefit, in terms of a higher wage, from agglomeration economies, workers do not have to commute to the main center of a polycentric metropolitan area. They will benefit as well if they work for a firm in the suburbs that benefits from interacting with firms at that center. Various empirical studies show that subcenters shape the internal structures of metropolitan areas significantly (Mills and Tan, 1980; Anas, Arnott and Small, 1998; McMillen and Smith, 2003; Rossi-Hansberg, Sarte and Owens, 2006). This indicates that the commuting-based delineations may understate the true sizes of metropolitan areas. As to the second condition, several externalities, including human-capital externalities and localized knowledge spillovers, are, in fact, found not to extend significantly beyond commuting distances in empirical studies (Anselin, Varga and Acs, 1997; Rosenthal and Strange, 2003, 2006; Bode, 2004). The pecuniary externalities arising from commodity trade are, however, found to affect wages significantly over distances of up to several hundred kilometers (Mion, 2004; Hanson, 2005). Commuting distances rarely exceed $50 \mathrm{~km}$ (e.g., Rouwendal and Rietveld, 1994). This indicates as well that the commuting-based delineations may understate the true sizes of metropolitan areas. 
The present paper suggests delineating metropolitan areas using an indicator that takes into account all forms of spatial interactions and interdependencies that generate or are induced by economies of urban agglomeration. This indicator is the amount by which the land price (or land rent) ${ }^{1}$ at any local administrative area is affected by economies of urban agglomeration. Since land is consumed by all economic agents, households as well as firms, and land is immobile and quasi fixed in supply, all economic benefits and costs will ultimately be monetized by land prices. By suggesting to use land prices as an indicator, this paper argues that the delineation of metropolitan areas should take into account not only those benefits and costs that arise from the economic interactions and interdependencies between agents, such as commuting, trade, or spillovers. It should also take into account the benefits and costs that arise from the interventions by local public administrations, such as higher local tax rates or tighter public zoning and environmental regulations in metropolitan areas. These interventions are considered as being consequences of urban agglomeration in the present paper. Higher tax rates, for example, are considered as reflecting the higher costs of providing public services that are complementary to urban agglomeration, and tighter public zoning and environmental regulations are considered as reflecting the preferences of the residents for protecting and preserving resources that are particularly scarce in densely populated areas.

The procedure for delineating metropolitan areas proposed here is formally quite similar to the procedures employed for delineating metropolitan areas by means of commuting intensities. The procedure identifies, in a first step, the centers of the metropolitan areas, and the degrees of economic integration between all local administrative areas and these centers. In a second step, the procedure delineates metropolitan areas by assigning those local administrative areas to a center that are more integrated with this center than with any other center. This procedure differs conceptually from the commuting-based delineation procedures in three important respects, however: The degree of economic integration within metropolitan areas is measured by land prices rather than by commuting intensities; metropolitan subcenters are accounted for explicitly; and the metropolitan centers and subcenters are identified endogenously rather than exogenously.

Following the economic theory of cities (Fujita, 1989; Fujita and Thisse, 2002), the indicator used here for measuring the degree of economic integration is the difference between the observed land price and the opportunity costs of urban land use. It will henceforth be labeled "urban land price." The opportunity costs are given by the "rural land price," which is, the land price that would prevail if the metropolitan center, or the whole metropolitan area, had never

\footnotetext{
${ }^{1}$ Focusing on land prices rather than land rents, the present paper argues that the expected future growth that is monetized (net of conversion costs) by the land prices (see Capozza and Helsley, 1990) is just another (dynamic) externality of urban agglomeration that should be taken into account when delineating today's metropolitan areas.
} 
existed, and all land were used for nonurban purposes. The urban land prices are interpreted here in a similar way as the equilibrium land prices in a model of a polycentric city. They reflect not only the net economic benefits spilling over from the centers of metropolitan areas, but also the net economic benefits spilling over from all other places in metropolitan areas. For expositional clarity, the urban land price in a local administrative area will nonetheless be said to be attributable to a center of a metropolitan area in this paper. In doing so, the centers are just considered as the formal representatives or geographical reference points of their metropolitan areas. If a local administrative area's land price is affected by more than one metropolitan area, its total urban land price is assumed to be the sum of the urban land prices attributable to the individual metropolitan centers.

The approach proposed here adopts the concept of circularly symmetric land price gradients from the economic theory of cities to estimate, for each local administrative area, the urban land prices attributable to all metropolitan centers. A similar concept is used for estimating population density gradients in metropolitan areas (Anas, Arnott and Small, 1998; McMillen and Smith, 2003). A land price gradient describes the value of the urban land price at any location as a function of just the location's distance from a metropolitan center. By assuming that the urban land price is the same in all places at the same distance from the center, the three-dimensional land price surface of a metropolitan area is mapped into a two dimensional function, the land price gradient.

In the present approach, the restrictive assumption that all metropolitan areas are circularly symmetric in geographical terms is relaxed somewhat by complementing the land price gradients of the metropolitan centers by additional land price gradients of metropolitan subcenters. A metropolitan subcenter is, metaphorically speaking, a local administrative area that multiplies the urban agglomeration economies spilling over from a metropolitan center. Each metropolitan subcenter is assigned a separate, circularly symmetric land price gradient that determines, for the subcenter itself as well as for any other local administrative area, the urban land price attributable to this subcenter. The urban land prices attributable to metropolitan subcenters are assumed to add to those attributable to metropolitan centers. For the purpose of delineating metropolitan areas, the urban land prices attributable to all subcenters in a metropolitan area are consolidated with the urban land price attributable directly to the center of this metropolitan area. This yields, for each local administrative area, an aggregate urban land price that is attributable directly or indirectly to a metropolitan center. This aggregate urban land price is used as the measure of the total degree of economic integration between a local administrative area and a metropolitan center in the approach proposed here.

Metropolitan subcenters play an important role in this approach for three reasons: First, they account for local peaks of the three-dimensional land price surface in metropolitan areas that cannot be accounted for by the 
two-dimensional land price gradients of the centers. Second, they account for circularly asymmetric metropolitan fringes that cannot be accounted for by the circularly symmetric land price gradients of the centers. And finally, they allow identifying the indirect economic linkages between metropolitan centers that are not integrated with each other directly. Metropolitan centers and subcenters are identified endogenously in the course of the regression used for estimating the land price gradients.

The land-price-based delineation approach is illustrated empirically by delineating metropolitan areas in West Germany. The illustration indicates that this approach tends to delineate fewer, but larger metropolitan areas in densely populated parts of the country and smaller metropolitan areas in sparsely populated parts than commuting-based delineation approaches. On aggregate, the population share in metropolitan areas delineated by means of the urban land prices tends to be smaller than that in metropolitan areas delineated by means of commuting intensities. The illustration also indicates that the approach sketched here is still based on some simplifying restrictive assumptions. One of these assumptions, which is found to affect the delineation results significantly, is that the land price gradients of all subcenters are of the same shape. Relaxing this assumption as far as possible is left to future research.

The paper is organized as follows. Section 2 introduces the delineation approach proposed in this paper. Section 3 presents the illustrative delineation of metropolitan areas in West Germany. Section 4 investigates the robustness of the delineation results obtained in Section 3, and Section 5 discusses directions for future research.

\section{CONCEPTUAL APPROACH}

\section{Overview}

The delineation of metropolitan areas proposed in this paper is done in two steps, which will be introduced in this section. In the first step, a cross-section regression that involves a variable-selection procedure is employed for identifying the metropolitan centers and subcenters, and simultaneously estimating the parameters of the land price gradients of these centers and subcenters. This regression divides the observed land prices in all local administrative areas within a country into two components: the urban land prices, represented in the regression model by all land price gradients for the metropolitan centers and subcenters, and the opportunity costs of urban land use, represented by the determinants of rural land prices. The urban land prices are, in addition, divided into the urban land prices attributable to the individual metropolitan centers or subcenters. The urban land prices attributable to the individual metropolitan centers or subcenters are represented by the individual center- or subcenter-specific land price gradients.

The land price gradients of the metropolitan centers are modeled as series of consecutive, concentric, and nonoverlapping distance bands around 
the centers. Each distance band is represented by a separate variable in the empirical model, the parameter of which is the urban land price attributable to the respective center at any place covered by the distance band. Modeling the land price gradients as distance bands is preferred over modeling them as continuous distance decay functions because distance bands impose weaker restrictions on the functional form of the land price gradients: the urban land price attributable to a metropolitan center is restricted to be the same at all places covered by a distance band but may vary freely across the distance bands. The land price gradients for the metropolitan subcenters are modeled in a more restrictive way, namely as inverse exponential distance decay functions. A land price gradient of a metropolitan subcenter is thus represented by just one variable in the empirical model.

The variable-selection procedure identifies the set of land price gradients that fit the spatial pattern of the observed land prices best, while keeping redundant gradients that do not contribute significantly to explaining the observed land prices outside the model. The procedure successively adds metropolitan centers, distance bands, or land price gradients of subcenters to the model, avoiding path dependency as far as possible. All parameters of these urban variables are restricted to be positive, that is, reflect the land price effects of positive net economies of urban agglomeration.

In the second step, the metropolitan areas are delineated by means of the degree of economic integration between each local administrative area and each metropolitan area, as indicated by the local administrative area's estimated urban land price attributable directly or indirectly to a metropolitan center. The direct effect is given by the land price gradient of the metropolitan center; the indirect effects are given by the land price gradients of the associated metropolitan subcenters. The metropolitan centers identified in the first step constitute the nodes of the metropolitan areas.

For expositional clarity, the regression approach that constitutes the first step of the delineation procedure will be introduced in two parts. First, the final regression model will be introduced. It is the regression model the selection procedure converges to. The number and locations of metropolitan centers and subcenters as well as the optimal number of distance bands around each metropolitan center will be assumed to be known for the time being. The variable-selection procedure will be introduced afterwards.

\section{The Regression Model}

For given sets of metropolitan centers, $\mathbf{J}$, and of metropolitan subcenters, $\mathbf{S}$, and for a given optimal number, $T_{j}$, of distance bands around each of the metropolitan centers in $\mathbf{J}$, the empirical model estimated in the first step of the delineation procedure can formally be expressed as

$$
P_{n}=\sum_{j \in \mathbf{J}} \sum_{\tau=0}^{T_{j}} \gamma_{j \tau} C_{j \tau n}+\sum_{s \in \mathbf{S}} \rho_{s} w_{n s}\left(\sum_{j \in \mathbf{J}} \sum_{\tau=0}^{T_{j}} \gamma_{j \tau} C_{j \tau s}\right)+\sum_{k=1}^{K} \alpha_{k} X_{k n}+u_{n} .
$$


Notation:

$$
\begin{aligned}
& n=1, \ldots, N \text { index of local administrative areas; } \\
& \mathbf{J}=\{1, \ldots, J\} \text { set of metropolitan areas and their centers, indexed by } j \text {; } \\
& \mathbf{S}=\{1, \ldots, S\} \text { set of metropolitan subcenters, indexed by } s ; \\
& \tau=0, \ldots, T_{j} \text { index of consecutive, concentric and nonoverlapping dis- } \\
& \text { tance bands around the } j^{\text {th }} \text { metropolitan center; the } 0^{\text {th }} \text { dis- } \\
& \text { tance band comprises the center itself; } \\
& P_{n} \text { land price in local administrative area } n \text {; } \\
& C_{j \tau n} \text { share of local administrative area } n \text { 's surface covered by the } \\
& \tau^{\text {th }} \text { distance band around the } j^{\text {th }} \text { metropolitan center; } \\
& X_{k n}(k=1, \ldots, K) \text { determinants of the rural land price in local } \\
& \text { administrative area } n \text {; } \\
& w_{n s} \text { spatial discounting factor for subcenter-specific land price } \\
& \text { gradients; } \\
& \gamma_{j \tau} \text { parameter reflecting the urban land price attributable to }
\end{aligned}
$$

The dependent variable, $P_{n}$, is the observed land price in local administrative area $n$ at a given point in time. The first two terms on the right-hand side of equation (1) estimate the urban land prices from land price gradients. The first term comprises the land price gradients of the $J$ metropolitan centers; the second the land price gradients of the $S$ metropolitan subcenters. The third term estimates the opportunity costs of urban land use from the determinants of rural land prices.

The land price gradient of the $j^{\text {th }}$ metropolitan center is represented by the term $\sum_{\tau=0}^{T_{j}} \gamma_{j \tau} C_{j \tau n}$ in equation (1). It comprises one explanatory variable, $C_{j \tau n}$, for each distance band around the $j^{\text {th }}$ center. The variable $C_{j \tau n}\left(0 \leq C_{j \tau n} \leq 1\right)$ is defined as the share of local administrative area $n$ 's surface covered by the $\tau^{\text {th }}$ distance band around the $j^{\text {th }}$ center. Its parameter, $\gamma_{j \tau}$, is the urban land price (in $€ / \mathrm{sqm}$ ) attributable to this center at all places covered by the $\tau^{\text {th }}$ distance band. The definition of the variables $C_{j \tau n}$ serves the purpose of accounting for unobserved land price differences within local administrative areas as far as possible. These variables are used here as weights of the urban land prices in the different parts of local administrative areas covered by the different 
distance bands. ${ }^{2}$ The innermost distance band, $\tau=0$, covers just the center's own surface. The variable $C_{j 0 n}$ is consequently a dummy variable. This distance band is not circularly symmetric. The subsequent distance bands, $\tau=1, \ldots, T_{j}$, cover the center's hinterland. Their outer boundaries are circularly symmetric around the center's midpoint. The $T_{j}^{\text {th }}$ distance band is highest-order distance band with a positive and significant urban land price attributable to the center. Its outer boundary marks the fringe of the metropolitan area represented by the center if there is no subcenter whose land price gradient extends beyond this outer boundary. The land price gradients of different metropolitan centers may overlap in local administrative areas that are affected by different metropolitan areas. In this case, a local administrative area's total urban land price is the sum of the (average) urban land prices attributable to the individual centers.

The land price gradients of the subcenters are represented by the second term on the right-hand side of equation (1), $\sum_{s \in \mathbf{S}} \rho_{s} w_{n s}\left(\sum_{j \in \mathbf{J}} \sum_{\tau=0}^{T_{j}} \gamma_{j \tau} C_{j \tau s}\right)$. They are supposed to account for local peaks of the metropolitan land price surface that are not explained by the land price gradients of the metropolitan centers. A local administrative area is considered a subcenter if it meets two conditions: First, it must be situated within a metropolitan area. This condition is met if the term in parentheses, $\sum_{j \in \mathbf{J}} \sum_{\tau=0}^{T_{j}} \gamma_{j \tau} C_{j \tau s}$ is significantly positive. This term is the sum of the subcenter's urban land prices attributable to all metropolitan centers. Second, a subcenter must generate additional urban agglomeration economies that impact significantly on its own land price as well as the land prices in its neighboring local administrative areas. This condition is met if the parameter $\rho_{s}$ is significantly positive. In contrast to those of the metropolitan centers, the land price gradients of the subcenters are reflected by just one variable in the model for simplicity. The parameter $\rho_{s}$ measures, consequently, the subcenter's effects on land prices in both the subcenter and its neighboring local administrative areas.

The bilateral spatial discounting factor $w_{n s}\left(0 \leq w_{n s} \leq 1\right)$ constitutes the land price gradient. It reflects the spatial decay of the land price effects with increasing distance of a local administrative area $n$ from the $s^{\text {th }}$ subcenter. The spatial discounting factor is defined such that it assumes the value of one at the subcenter itself, that is, $w_{n s}=1$ for $n=s$, and decreases continuously with increasing distance from the subcenter. This definition allows interpreting the parameter $\rho_{s}$ as a measure of the effects of urban agglomeration economies on

${ }^{2}$ If, for example, 40 percent of local administrative area $n$ 's surface is covered by the first distance band around the $j$ th center, that is, $C_{j 1 n}=0.4$, and the remaining 60 percent by the second distance band, that is, $C_{j 2 n}=0.6$, this local administrative area's average urban land price attributable to the $j^{\text {th }}$ center will be the weighted average of the distance band-specific urban land prices, $\gamma_{j 1} 0.4+\gamma_{j 2} 0.6 € / \mathrm{sqm}$. If the local administrative area's surface is covered entirely by the first distance band around the center, that is, $C_{j 1 n}=1$, its average urban land price attributable to the center will be just $\gamma_{j 1} € / \mathrm{sqm}$. And if, finally, 40 percent of the local administrative area's surface is covered by the highest-order $\left(T_{j}\right.$ th) distance band around the center, and the remaining 60 percent are not covered by a distance band, this area's average urban land price attributable to the center will be $0.4 \gamma_{j T j} € /$ sqm. 
the subcenter's own land price. It is actually a multiplier in the present case: it reflects the percentage by which a subcenter's total urban land price exceeds its urban land price attributable to metropolitan centers. To see this, notice that, for $w_{n s}=1$, the total urban land price in the subcenter $s$ is

$$
\sum_{j \in \mathbf{J}} \sum_{\tau=0}^{T_{j}} \gamma_{j \tau} C_{j \tau s}+\rho \sum_{j \in \mathbf{J}} \sum_{\tau=0}^{T_{j}} \gamma_{j \tau} C_{j \tau s}=(1+\rho) \sum_{j \in \mathbf{J}} \sum_{\tau=0}^{T_{j}} \gamma_{j \tau} C_{j \tau s},
$$

where the term $\sum_{j \in \mathbf{J}} \sum_{\tau=0}^{T_{j}} \gamma_{j \tau} C_{j \tau n}$ is just the subcenter's urban land price attributable to metropolitan centers.

The spatial discounting factor, $w_{n s}$, can be interpreted analogously to iceberg transport costs: the larger the distance between the subcenter $s$, the point of departure of the iceberg, and any other local administrative area $n$, the point of destination of the iceberg, the larger the diffusion losses. The iceberg is, in the present case, the amount by which the subcenter impacts on its own land price, $\rho \sum_{j \in \mathbf{J}} \sum_{\tau=0}^{T_{j}} \gamma_{j \tau} C_{j \tau s} € /$ sqm. In the illustration below, the spatial discounting factor will be determined by an inverse exponential distance-decay function, the distance-decay parameter of which, denoted by $\delta$, will be estimated endogenously but assumed to be the same for all subcenters.

Finally, rural land prices, determined by the third term in equation (1), are estimated endogenously to determine the "zero point" for the urban land prices separately for each local administrative area. The rural land prices depend on the availability of local consumption amenities, resulting, among others, from favorable climatic conditions or a high recreational value of the area (Roback, 1982), and on the productivity of farming, resulting, among others, from a high quality of the soil or large farm and field sizes.

\section{Estimation: The Variable-Selection Procedure}

Rather than determining the locations of the metropolitan centers and subcenters ex ante, the approach proposed here uses a variable-selection procedure to identify them in the course of the estimation of the empirical model (1). ${ }^{3}$ In addition to the metropolitan centers and subcenters, the selection procedure identifies the optimal number of distance bands for each metropolitan area.

The selection procedure used here presupposes a three-tiered hierarchy of locations within metropolitan areas. At the top of the hierarchy are the centers of metropolitan areas. An administrative area added to the model as a metropolitan center creates a new metropolitan area by definition. This center constitutes the $0^{\text {th }}$ distance band of the land price gradient of the metropolitan

${ }^{3}$ See McMillen and Smith (2003) for a discussion of methods for identifying metropolitan centers and subcenters employed in the density gradients literature. Mori, Nishikimi and Smith (2005), and Mori and Smith (2006) propose a selection strategy for identifying industrial clusters that is based on a probabilistic model. This strategy is, however, not suited for estimating the urban and rural land prices simultaneously. 
area. The metropolitan centers are selected from a set of "candidate" metropolitan centers, which must be determined ex ante. This set of candidate centers may be fairly broad. It may, for example, comprise all (larger) cities, or all local administrative areas that exhibit some net in-commuting. It should, however, not comprise local administrative areas with high land prices that are obviously not related to urban agglomeration economies, and that cannot be explained by the determinants of the rural land prices. These local administrative areas will probably be misinterpreted as being metropolitan centers by the selection procedure. On the second tier are the hinterlands of the metropolitan areas, represented by the distance bands of order one or higher around each center in the model. And on the third tier are the metropolitan subcenters. All administrative areas covered at least partly (by 30 percent in the illustration below) by a distance band of an order greater than 0 in the model are considered candidate subcenters. The selection procedure takes this hierarchy into account in 11 iterations to prevent metropolitan areas from being fragmented.

The selection procedure is a stepwise, forward/backward selection procedure. ${ }^{4}$ As a general rule, the procedure either adds one variable to the regression model, or removes one or more variables from the regression model in each iteration. The variable to be added to the model may be either a metropolitan center not yet in the model, the next higher order distance band of a land price gradient of a metropolitan center in the model, or the land price gradient of a subcenter. The variable or variables to be removed from the model may be either the land price gradient of a subcenter, the highest-order distance band or distance bands of a land price gradient of a metropolitan center in the model, or a metropolitan center itself. Several, or even all, variables belonging to the same metropolitan area may be removed simultaneously. The selection procedure is designed such that it has greater opportunities for removing variables than for adding variables for two reasons. First, the greater opportunities for removing variables from the model reduce the risk of path dependency of the selection procedure. Any selection procedure entails the risk of path dependency. The choices in earlier iterations may impact significantly on the choices in subsequent iterations, and may direct the selection procedure to a local rather than the preferred global optimum. To reduce the risk of path dependency as far as possible, each and every variable in the model is considered for exclusion in each iteration. And second, the greater opportunities for removing variables prevent the model from keeping redundant variables. Variables added to the model may loose their explanatory power in the course of the subsequent iterations. This may be true for single variables or even for all variables representing a metropolitan area. Therefore, the selection procedure considers for exclusion not only the variable added in the previous iteration but all variables currently in the model.

The selection procedure starts with a model comprising only the rural variables (including the constant term). The rural variables are forced into the

${ }^{4}$ The SAS code is available from the author upon request. 
model in all iterations. In the first iteration, one of the candidate metropolitan centers is added. In the second iteration, this metropolitan center may be complemented by its first-order distance band; another center may be added; or the center added in the first iteration may be removed. If the first-order distance band is added, the third iteration takes one of the following five actions: (i) adding a second metropolitan center; (ii) adding the next higher order distance band to the distance band in the model; (iii) adding one of the local administrative areas covered by the first-order distance band as a subcenter; (iv) removing the first-order distance band; or (v) removing jointly the metropolitan center and its first-order distance band. The set of possible actions thus changes with each iteration.

In each iteration, each possible action requires running a separate auxiliary regression. Based on the results of all auxiliary regressions, the procedure chooses the action that yields the highest improvement of the adjusted $R^{2}$ under the restriction that all parameters of the land price gradients are nonnegative. The selection procedure terminates if no possible action improves the adjusted $R^{2}$. The adjusted $R^{2}$ is chosen here as a decision criterion for simplicity. Other selection criteria, such as the Akaike information criterion or the Schwarz criterion, may be used instead. The sign restrictions for the parameters of the land price gradients serve two purposes. First, they prevent the selection procedure from misinterpreting very low land prices as being due to agglomeration diseconomies. This may happen if the land price in a local administrative area situated in the vicinity to a metropolitan center is significantly lower than its predicted rural land price. This paper assumes that all land whose price is below the predicted rural land price is used for nonurban purposes. And second, the sign restrictions prevent the model from fitting the data perfectly. Notice that the number of variables that may be added to the model-all candidate metropolitan centers, a large number of distance bands for each center, and every administrative area covered by at least one of those distance bandsexceeds the number of observations in the dataset by far.

The sign restrictions invalidate, however, the usual inferential statistics, such as standard deviations or t-values. The distributional properties of the parameters are actually unknown. The estimated variance-covariance matrix of the parameters is consequently not available for determining the significance of the urban land prices predicted from the parameter estimates in the second step of the delineation procedure. This significance would help decide whether or not an administrative area is part of a metropolitan area. Developing alternative inferential statistics based, for example, on the bootstrap is left to future research.

\section{Delineation of Metropolitan Areas}

The second step of the approach proposed here delineates the metropolitan areas, using the results of the first-step regression as an input. The objective is to assign each local administrative area with a positive and significant urban 
land price to exactly one metropolitan area, and to assign no administrative area with a zero or insignificant urban land price to any metropolitan area.

From equation (1), administrative area $n$ 's urban land price attributable to metropolitan center $j$ can be calculated as

$$
P_{n, \text { urban }}^{j}=\sum_{\tau=0}^{T_{j}} \gamma_{j \tau} C_{j \tau n}+\sum_{s \in \mathbf{S}} \rho_{s} w_{n s}\left(\sum_{\tau=0}^{T_{j}} \gamma_{j \tau} C_{j \tau s}\right),
$$

and the total urban land price in administrative area $n$ as

$$
P_{n, \text { urban }}=\sum_{j \in \mathbf{J}} P_{n, \text { urban }}^{j}=\sum_{j \in \mathbf{J}} \sum_{\tau=0}^{T_{j}} \gamma_{j \tau} C_{j \tau n}+\sum_{s \in \mathbf{S}} \rho_{s} w_{n s}\left(\sum_{j \in \mathbf{J}} \sum_{\tau=0}^{T_{j}} \gamma_{j \tau} C_{j \tau s}\right) .
$$

The two urban land prices in equations (2) and (3) can be estimated by using the results of the first-step regression approach: the sets of the metropolitan centers, $\hat{\mathbf{C}}$, and subcenters, $\hat{\mathbf{S}}$, the optimal numbers of distance bands, $\hat{T}_{j}$, and the estimated parameters of all land price gradients, $\hat{\gamma}_{j \tau}, \hat{\rho}_{s}$, and $\hat{\delta}$.

The predicted total urban land price in equation (3) is used to distinguish metropolitan from nonmetropolitan local administrative areas. If it is significantly positive, the local administrative area is part of a metropolitan area. The significance of this urban land price should ideally be determined by means of its standard deviation. It may be assumed to be significantly greater than zero if its statistical probability of being zero is estimated to be less than 5 percent or 10 percent. If the distributional properties of the predicted urban land prices are unknown, which is the case here (see above), the significance has to be determined ad hoc by, for example, specifying a threshold urban land price.

The predicted urban land price attributable to a metropolitan center in equation (2) is used to determine which metropolitan area a local administrative area with a significant urban land price is assigned to. As a general rule, the local administrative area should be considered part of that metropolitan area that impacts strongest on its land price, as evidenced by the predicted urban land price attributable to this metropolitan center. This general rule can be employed as well if one metropolitan center impacts on the land price of another metropolitan center. It suggests merging the two metropolitan areas. The rule may, however, be amended such that the two metropolitan areas are merged only if the second center's urban land price attributable to the first center is significantly different from zero. If the standard deviations of the predicted urban land prices in equation (2) are known, the significance of this urban land price can be determined. Alternatively, the significance may be determined ad hoc again by specifying a threshold urban land price.

Equation (2) shows how the urban land prices attributable to metropolitan subcenters are consolidated with those attributable to metropolitan centers in order to ultimately attribute the urban land prices to the metropolitan centers only: the amount by which a subcenter affects the land prices in any 
of its neighboring local administrative areas is assigned proportionally to the metropolitan centers that affect the land price at the subcenter. The proportions are given by the relative magnitudes by which the metropolitan centers affect the subcenter's urban land price.

\section{EMPIRICAL ILLUSTRATION: METROPOLITAN AREAS IN WEST GERMANY}

This section illustrates the delineation procedure introduced in the previous section by delineating metropolitan areas in West Germany. West Germany is particularly interesting for an illustrative case study because the number and the geographical sizes of metropolitan areas are not obvious when glancing at a map. There are, on the one hand, several geographical clusters of larger cities within densely populated areas, such as the Rhine-Ruhr or the Rhine-Main-Neckar areas. These areas are usually divided into several metropolitan areas or labor market areas by means of commuting intensities. The Rhine-Ruhr area, for example, comprises nine FURs (see Cheshire and Hay, 1989, Table A12), or five labor market areas (Eckey, Kosfeld and Türck, 2006, Figure 3). It will be interesting to see to what extent the delineation procedure proposed here is able to cope with these complex systems of cities, and to what extent it uses the option of flagging subcenters to capture the economic interactions and interdependencies between these cities. On the other hand, there are a significant number of cities situated within predominantly rural areas with a low-population density. While there is usually some commuting to those cities from their neighboring local administrative areas, the neighboring local administrative areas as a whole are not too urbanized. It will be interesting to see how far, in geographical terms, the delineation procedure suggests the metropolitan areas of these cities to extend into their hinterlands.

In defining local administrative areas, which are the basic geographical units of the analysis, the illustration follows the commuting-based delineations of metropolitan areas. For practical reasons, most commuting-based delineations, including the delineation of FURs and labor market areas, choose as their basic units the lowest level of local administrative areas for which a greater variety of statistical indicators is publicly available. This level is the Landkreise and kreisfreie Städte in Germany. The German Landkreise and kreisfreie Städte are, like U.K. counties and French départements, classified as NUTS3 regions. They are broadly comparable to counties in the U.S. The choice of county-level administrative areas as the basic units of the delineation ensures that the main statistical indicators used frequently for urban planning and research purposes are available for metropolitan areas. It is, however, suboptimal from a research perspective. County-level administrative areas are too large for the purpose of delineating metropolitan areas appropriately because county-level commuting or land price aggregates mask significant local differences between municipalities. 
East Germany, including Berlin, is excluded from the analysis because the East German land markets are still far from being in equilibrium. There is a huge excess supply of housing in East Germany (Dohse et al., 2002).

\section{Data}

The dataset used to delineate metropolitan areas comprises observations for all 326 West German Landkreise and kreisfreie Städte (labeled "counties" henceforth). The average size of the 326 counties is $781.3 \mathrm{sqkm}$; their average population density 518 inhabitants per sqkm.

The set of candidate metropolitan centers from which the selection procedure selects the metropolitan centers is either the 112 centers of the West German labor market areas defined by Eckey, Kosfeld and Türck (2006) or the 91 West German city-counties. The 112 centers of the labor market areas, which are used as candidate metropolitan centers in the approach estimated in this section, are those counties that are found to engender the greatest amount of commuting by Eckey, Kosfeld and Türck. ${ }^{5}$ The 91 West German city-counties (kreisfreie Städte), which are used for a robustness check in Section 4, comprise just a single urban municipality. Almost all larger cities in West Germany are city-counties. City-counties are, on average, much smaller in geographic terms than the 235 Landkreise (148.2 sqkm, compared to $1,001.3 \mathrm{sqkm}$ ) but their average population density is much higher (1,366.4 inhabitants per sqkm, compared to 223.3). Their population sizes range from about 40,000 to about 1.7 million.

The land prices, denoted by $P_{n}$ in equation (1), are measured in terms of the prices (in constant 2000 euros) per square meter paid for unimproved residential sites on average over the period 1995 to $2001 .{ }^{6}$ Unimproved residential sites are assumed to be a homogeneous good. In contrast to the prices of improved residential sites, the prices of unimproved residential sites can be expected to be affected not too strongly by quality differences. The characteristics of the local neighborhoods may be of some influence, though. Moreover, the observed

\footnotetext{
${ }^{5}$ Eckey, Kosfeld and Türck (2006) aggregate the 326 West German counties into 112 labor market areas by means of their bilateral commuting intensities, using a factor analysis. The factor analysis determines the eigenvalues and their associated eigenvectors of a matrix of association coefficients for the commuting intensities. Each eigenvector associated with an eigenvalue greater than one is taken to represent one labor market area. The counties with the highest factor loadings in these eigenvectors are chosen to be the centers of these labor market areas.

${ }^{6}$ Land sales statistics are available from the GENESIS database of the German Federal Statistical Office. They report, for each county, the number of the annual transactions as well as the aggregate annual trade volume (in sqm) and trade value (in euros). To limit the influence of outliers, the annual volumes and values are aggregated over the years 1995-2001. The annual trade values are deflated by the national consumer price index. The number of transactions varies considerably across the counties, with a minimum of six and a maximum of 11,868 (average 1,384) over the period of seven years. The land price for Hamburg, which is not available from the GENESIS database or any other public data source, is set arbitrarily to $€ 600$. This choice does not affect the regression results because Hamburg is always selected as a center, which implies that it is assigned a separate dummy variable.
} 
prices of unimproved residential sites are assumed to be the equilibrium land prices that equate the supply and the aggregate demand by both households and firms.

The variables of the land price gradients of the metropolitan centers, denoted by $C_{j \tau n}$ in equation (1), are calculated as the shares in the counties' surfaces of up to 10 distance bands around the geographical midpoints of the 112 centers of labor market areas (or the 91 city-counties). ${ }^{7}$ The first distance band covers the first $20 \mathrm{~km}$ from a center's or city-county's midpoint, exclusive of the center's or city-county's area. The higher order distance bands cover $10 \mathrm{~km}$ each.

The land price gradients of the metropolitan subcenters are modeled as exponential distance decay functions, ${ }^{8}$ defined as

$$
w_{n s}:= \begin{cases}1 & \text { for } n=s \\ \exp \left(-\delta D_{n s}\right) & \text { for } n \neq s \text { and } D_{n s} \leq D_{\max } \\ 0 & \text { for } n \neq s \text { and } D_{n s}>D_{\max } .\end{cases}
$$

$\delta$ denotes the distance decay parameter, which reflects the distance costs, $D_{n s}$ the Euclidean distance between the midpoints of any county, $n$, and any subcenter, $s$, and $D_{\max }$ a distance threshold that limits the geographical size of the gradient to a plausible range. The distance decay parameter, $\delta$, is estimated endogenously but assumed to be the same for all subcenters for simplicity. Investigating opportunities for relaxing this restrictive assumption is left to future research, although it is shown to affect the delineation of metropolitan areas significantly (see Section 4). Notice that the distance decay parameter must be subjected to some restriction in order to prevent the regression from turning the land price gradient of a subcenter into a dummy variable for the subcenter. The value of the distance decay parameter is restricted to the interval $0.019<\delta<0.21$ to prevent it from assuming implausibly low or high values. The distance threshold is set to $D_{\max }=50 \mathrm{~km}$, which is roughly equivalent to a 1 hour's trip by car or commuter train (with frequent stops) within metropolitan areas. According to the 2004 microcensus, 95 percent of all commuting in Germany takes place within distances of less than $50 \mathrm{~km}$. The distances, $D_{n s}$, may alternatively be measured in terms of travel time rather than Euclidean distances. Travel time distances can, on the one hand, be expected to proxy

${ }^{7}$ To determine these shares, the West German area is divided into a system of regular grid points (one point per sqkm). The border coordinates of the counties available from the SAS software package are used to assign the grid points to counties. Euclidean distances are used to assign the grid points to the centers' or city-counties' midpoints. The coordinates of the midpoints were kindly provided by the Bundesanstalt für Bauwesen und Raumordnung. The share of a distance band in a county's area is approximated by the share of joint grid points in all grid points within the county.

${ }^{8}$ Papageorgiou and Pines (1989) discuss the conditions for the urban bid-rent function to take the functional form given in equation (4) in a model of a monocentric city. Inverse exponential distance weights have been used widely in the density gradient literature (Mills and Tan, 1980; Anas, Arnott and Small, 1998). The distance threshold helps prevent the regression procedure from picking up random correlations of the land prices between counties over longer distances. 
the economic distances more appropriately than Euclidean distances because they account for topographical barriers like rivers or mountains as well as for the quantity and quality of the infrastructure. On the other hand, they may be subject to endogeneity concerns (see, e.g., Cohen and Morrison Paul, 2007).

The determinants of rural land prices, finally, denoted by $X_{k n}$ in equation (1), are proxied by a constant term as well as by indicators of consumption amenities and farming productivity. All these determinants are chosen such that they are exogenous to the land prices to avoid additional complexities arising from instrumenting endogenous explanatory variables. Consumption amenities are proxied by three variables. An index of the variation of altitudes (relief intensity; variable RELIEF INTENS) proxies for the general scenic attractiveness of the landscape; a dummy variable for counties in the Alps (MOUNTAIN) proxies for the specific touristic attractiveness of mountainous landscapes; and the mean annual sunshine radiation (in $\mathrm{kWh} / \mathrm{sqm}$; SUNSHINE) proxies for climatic amenities. ${ }^{9}$ The productivity of farming is proxied by three variables as well. The official index of the fertility of the soil proxies for the general profitability of farming. This index, which ranges from 0 (worst quality) to 100 (loess), enters the model in levels and squares (SOIL, SOILSQ). The squared term captures decreasing returns to soil quality, as measured by the official index. And finally, a variable indicating the dominant form of inheritance of farms in the past (INHERIT) proxies for the average farm and field sizes. The farms and fields tend to be smaller, and the agricultural productivity lower, in regions where the farms and fields were fragmented by partible inheritance in the past. The variable INHERIT takes the value of 1 for counties where primogeniture was the dominant form of inheritance in the past;-1 for counties where partible inheritance was the dominant form; and 0 for counties where other forms of inheritance dominated, or where the forms of inheritance were mixed. ${ }^{10} \mathrm{~A}$ positive parameter of the variable INHERIT will consequently indicate that agricultural productivity raises the land prices in counties where farms and fields are not fragmented due to partible inheritance.

\section{Regression Results}

The regression results for equation 1 are summarized in Table 1 . The detailed regression results, including all parameter estimates, are reported in

\footnotetext{
${ }^{9}$ For Germany, Rehdanz and Maddison (2004) find a positive relationship between climatic conditions and housing prices. Higher relief intensity may, in addition to generating consumption amenities, limit the supply of arable land available for residential or commercial purposes. This shortage of arable land may, ceteris paribus, also raise land prices. Data on relief intensity were kindly provided by the Bundesanstalt für Bauwesen und Raumordnung. The data on sunshine radiation and the concentration of cultural sites are from the "Study Programme on European Spatial Planning" (SPESP) dataset. All these data are available at the level of the 31 West German NUTS2 regions.

${ }^{10}$ The data on soil quality were kindly provided by the Bundesanstalt für Bauwesen und Raumordnung. The data on the forms of inheritance in the past are inferred from Figure 1 in Abel (1955).
} 
TABLE 1: Summary of Regression Results for equation (1)

\begin{tabular}{lcc}
\hline \hline \# Parameters & & 98 \\
Metropolitan centers & $(J)$ & 52 \\
Distance bands & $\left(\Sigma_{j} T_{j}\right)$ & 25 \\
Subcenters & $(S)$ & 13 \\
Distance decay parameter & $(K)$ & 1 \\
Rural variables & $\left(\Sigma_{j \in J} T_{j}\right)$ & 7 \\
\# Distance bands & $(J)$ & 25 \\
\# Metropolitan centers & $\left(T_{j}=0\right)$ & $52(100 \%)$ \\
With 0 distance bands (metro center) & $\left(T_{j}=1\right)$ & $35(67.3 \%)$ \\
With 1 distance band $(\leq 20 \mathrm{~km})$ & $\left(T_{j}=2\right)$ & $11(21.2 \%)$ \\
With 2 distance bands $(\leq 30 \mathrm{~km})$ & $\left(T_{j}=3\right)$ & $4(7.7 \%)$ \\
With 3 distance bands $(\leq 40 \mathrm{~km})$ & & $2(3.8 \%)$ \\
\# Counties & & $326(100 \%)$ \\
With urban land price $>0$ & & $167(51.2 \%)$ \\
With urban land price $=0$ & & $159(48.8 \%)$ \\
Predicted rural land prices (all counties) & & \\
Mean & & 63.97 \\
Minimum & & 14.97 \\
Maximum & & 195.32 \\
adj. $R^{2}$ & & 0.898 \\
Sum of squared residuals $(\times 1,000)$ & & 351 \\
\# Iterations of selection procedure & & 94 \\
\hline
\end{tabular}

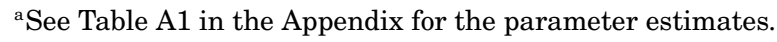

Table A1 in the Appendix. The selection procedure terminated successfully after 94 iterations. In the course of these iterations, 92 variables representing metropolitan centers, distance bands, or subcenters were added to the model. Two of these variables were dropped again from the model in a subsequent iteration. The adjusted $R^{2}$ of 0.9 indicates that the preferred model explains the variation of land prices across local administrative areas in West Germany pretty well.

Of the 112 centers of labor market areas that are specified as candidate metropolitan centers, the selection procedure considers only 52 as metropolitan centers. The land prices at the remaining 60 centers of labor market areas are either estimated to not exceed the estimated rural land prices or are attributable to other metropolitan centers. A map of the estimated urban land prices is depicted in the left-hand side graph of Figure A2 in the Appendix; the corresponding numbers for each metropolitan county are given in Table A2.

Similar to Brakman, Garretsen and Schramm (2004), who investigate the effects of the market potential on land prices in Germany, the urban land prices attributable to metropolitan centers are estimated to decay fairly rapidly with increasing distances from most of these centers in the present illustration. About two-thirds (35) of the 52 metropolitan centers are estimated to have no metropolitan hinterland at all. They are not assigned a single distance band 
outside the metropolitan center by the selection procedure. Most of these metropolitan centers are smaller cities surrounded by mostly rural counties. Another 11 metropolitan centers do not impact on land prices at distances of more than $20 \mathrm{~km}$ (first distance band), and only two metropolitan centers, Stuttgart and Düsseldorf, impact on the land prices at distances of more than $30 \mathrm{~km}$ (up to $40 \mathrm{~km}$; third distance band), according to the estimates. A closer inspection of the estimated parameters of the distance-band variables, $\gamma_{j \tau}$, suggests that the land price effects do, in fact, not decrease continuously with increasing distance to the centers (see Table A1 in the Appendix). The estimated parameters for the three distance bands around the city of Düsseldorf, for example, exhibit a local peak at a distance of 20-30 km from downtown Düsseldorf (second distance band). And those around the city of Stuttgart exhibit a local peak at a distance of $30-40 \mathrm{~km}$ (third distance band). These local peaks indicate that modeling the land price gradients at metropolitan centers in terms of distance bands is, in fact, preferable over modeling them in terms of continuous distance decay functions.

The selection procedure also identifies 13 subcenters. Most of these subcenters are assigned to the larger metropolitan centers: five subcenters are assigned to Düsseldorf, two to Munich, and another two jointly to Frankfurt and Wiesbaden. The distance decay parameter $(\delta)$ is estimated to be 0.025 , which implies a half-life distance of the effects of the spillovers from subcenters on urban land prices of about $28 \mathrm{~km}$. The spillovers from the subcenters are thus estimated to extend across longer distances than those from most of the metropolitan centers. This implies that the spillovers from subcenters shift the fringes of metropolitan areas significantly beyond the areas covered by the land price gradients of the metropolitan centers. Most of the estimates for the parameters $\rho_{s}$, are within plausible ranges (0.4-7.3; see Table A1 in the Appendix), which implies that the urban agglomeration economies at the subcenters add another 40-730 percent to the urban land prices attributable to the metropolitan centers. There is, however, one "outlier," Bochum, for which the parameter $\rho_{s}$ is estimated to be 247. This high parameter suggests that Bochum may actually be a metropolitan center rather than a subcenter. The urban agglomeration economies that impact on Bochum's land price appear to originate primarily from the city itself rather than from other cities or counties.

The seven proxies that explain the rural land prices suggest that the consumers' preferences for an attractive climate (SUNSHINE) and a scenic landscape (RELIEF'INTENS; MOUNTAIN) are reflected in higher land prices, as are higher agricultural productivity due to better soil (SOIL, SOILSQ) and larger farm and field sizes (INHERIT). See Table A1 in the Appendix for the parameter estimates, and the right-hand side map in Figure A1 for the estimated rural land prices. Taken together, the rural land prices are estimated to be about $€ 64$, on average, across all administrative areas, rural and urban. This average includes the estimates for the administrative areas in the Alps, where tourism and the limited availability of arable land drive the land prices up. 


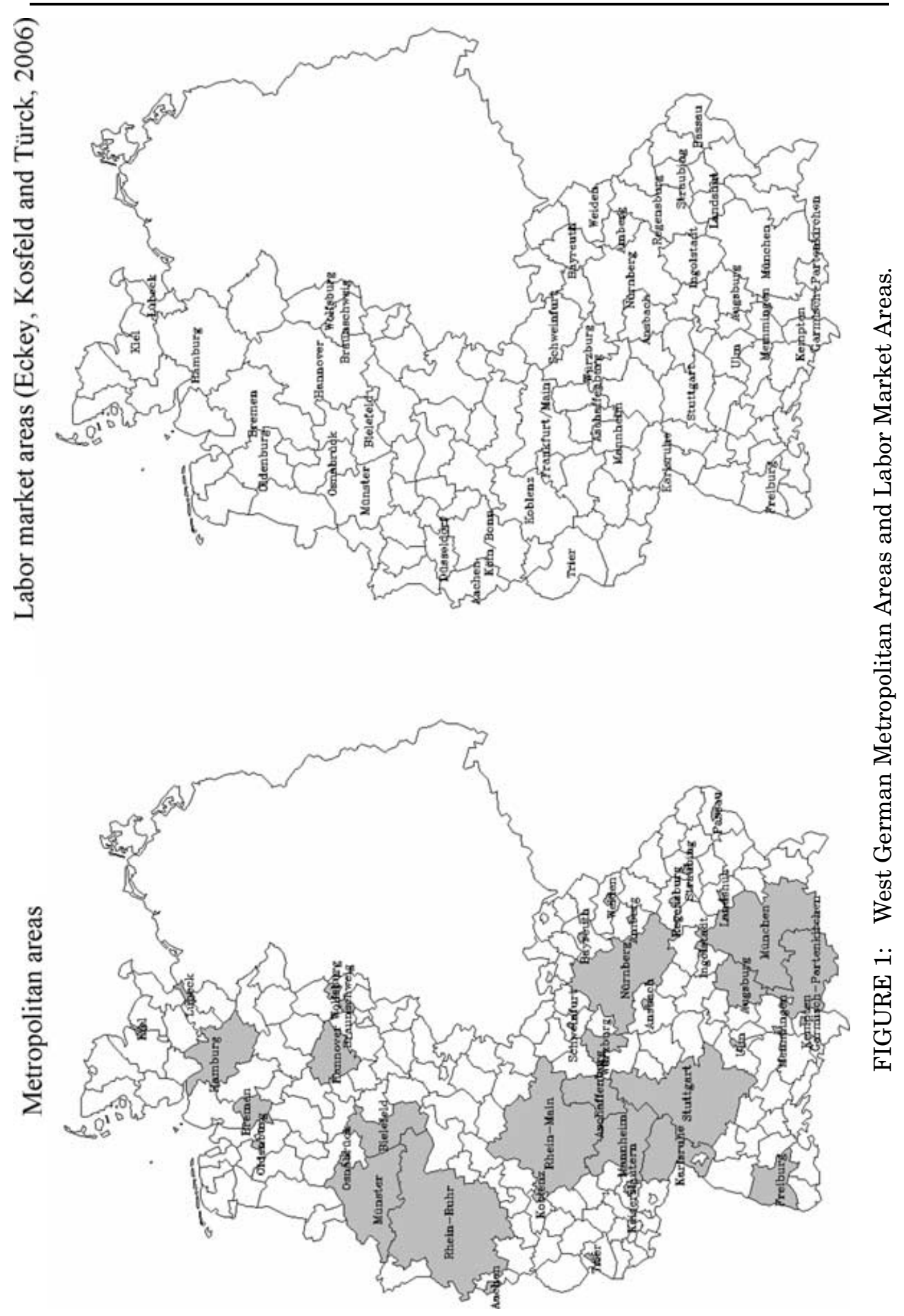

(C) Blackwell Publishing, Inc. 2008. 


\section{Delineation of Metropolitan Areas}

This subsection illustrates the second step in the delineation procedure proposed in this paper. It delineates metropolitan areas in West Germany, using the regression results just presented, and applying the delineation rules described in Section 2. The estimated urban land prices attributable directly or indirectly to the metropolitan centers (see equation 3 ) are assumed to be significantly different from zero only if they amount to at least $€ 20$. The estimated urban land prices attributable to individual metropolitan centers (see equation 2) are taken at face value. Their significance threshold is assumed to be zero for simplicity.

The delineation yields 40 metropolitan areas in West Germany (Figure 1; left-hand side map). The detailed assignment of the counties to the 40 metropolitan areas is given in Table A2 in the Appendix. Of the 52 metropolitan centers identified by the regression analysis in the first step, 12 are merged with other metropolitan centers into joint metropolitan areas. These metropolitan centers are merged for several reasons: nine of the 12 metropolitan centers are merged to other metropolitan areas because their land prices are estimated to be affected directly by those other metropolitan areas. The remaining three metropolitan centers are merged to other metropolitan areas because their land prices are estimated to be affected indirectly by those other metropolitan areas, namely through subcenters of those other metropolitan areas. To give an example, the Rhine-Ruhr metropolitan area (10 in Table A2) comprises a total of five cities identified as separate metropolitan centers by the regression: Düsseldorf, Essen, Krefeld, Cologne (Köln), and Dortmund. It comprises, in addition, five cities or counties identified as subcenters: Bochum, Erftkreis, Oberhausen, Rheinisch-Bergischer Kreis, and Viersen. All five subcenters are assigned to Düsseldorf as their metropolitan center. Düsseldorf is in fact estimated to be the most influential among the centers in the Rhine-Ruhr area. Three of the four other metropolitan centers, Essen, Krefeld, and Cologne, are covered by Düsseldorf's land price gradient, which indicates that their land prices are affected directly by urban agglomeration economies attributed to Düsseldorf. This is a sufficient condition for considering Düsseldorf, Essen, Krefeld, and Cologne to be members of the same metropolitan area, according to the delineation rules set up in Section 2. The fifth metropolitan center, Dortmund, is not covered by Düsseldorf's land price gradient. It is, however, covered by the land price gradients of two of Düsseldorf's subcenters, Oberhausen and Bochum, which indicates that Dortmund's land price is affected indirectly by urban agglomeration economies attributable to Düsseldorf. This is a sufficient condition to consider Düsseldorf and Dortmund to be members of the same metropolitan area as well, according to the delineation rules.

Comparing the metropolitan areas delineated here to the metropolitan areas in the U.S., the FURs in Western Europe, and the labor market area in Germany indicates that the urban land prices tend, on aggregate, to be a more restrictive criterion for delineating metropolitan areas than the commuting 
intensities. The share of the 40 West German metropolitan areas delineated here in the total population is about 64 percent, which is significantly lower than the shares of the metropolitan areas in the U.S. (more than 80 percent), or those of the European FURs. The larger among the European FURs alone account for about 70 percent (see Cheshire and Hay, 1989). ${ }^{11}$

This result is, at the first view, surprising because the land-price-based delineation procedure is supposed to capture interactions between firms that propagate over longer distances than commuting. The metropolitan areas delineated by means of urban land prices should, from this perspective, account for a larger share of the total population. Two reasons may jointly explain why they do not. The first reason is that longer distance interactions between firms may impact stronger on land prices at the centers and subcenters than on those at the fringes of metropolitan areas. Either the firms situated further from the centers do not interact too intensively with firms at the centers, or their benefits from these interactions are too low to impact significantly on the land prices because the density of firms (per sqkm) is too low. The interactions between firms across longer distance may actually be interactions primarily between firms situated at different centers or subcenters. This may contribute to explaining why the land-price-based delineation approach suggests merging neighboring metropolitan areas into polycentric metropolitan areas more frequently than commuting-based delineation approaches. Recall that the Rhine-Ruhr area, which is found to be a single, polycentric metropolitan area here, comprises no less than nine FURs, or five labor market areas.

The second reason is probably due to the fact that the indicator of urban land prices assigns, ceteris paribus, a lower weight to urbanized municipalities in counties at the metropolitan fringes. Counties at the metropolitan fringes frequently comprise both urbanized municipalities, located at the borders towards the metropolitan areas, and rural municipalities, located at larger distances from the metropolitan areas. In terms of both indicators, the urban land prices and the commuting intensities, the urbanized municipalities will be more highly integrated with a metropolitan area than the rural municipalities. The urbanized municipalities will, however, be assigned lower weights in the average, county-level land prices than in the average, county-level commuting intensities because their shares in the counties' areas are lower than their shares in the counties' workforces. A comparison of the West German metropolitan areas delineated here (Figure 1, left map) to the West German labor market areas (Figure 1, right map) tends to support this reason. Virtually all metropolitan areas in the less densely populated regions, such as the northern

${ }^{11}$ The larger European FURs are those with a population size of 330,000 or more in 1981. The metropolitan areas with a population of 330,000 or more delineated here account for only 59 percent of the total West German population. If the significance threshold for the urban land prices were reduced from $€ 20$ to $€ 0$, such that all counties with a positive estimated urban land price were considered parts of a metropolitan area, the population share of the largest metropolitan areas delineated here would be 67 percent, which is still lower than that of the largest FURs. 
and eastern parts of West Germany, tend to be smaller than the corresponding labor market areas. ${ }^{12}$ While most of the metropolitan areas are estimated to comprise just the metropolitan centers, the corresponding labor market areas frequently comprise, in addition to the centers, another one or two counties. Many of these counties are not entirely urbanized. To better determine the reasons why the land-price-based delineation proposed here covers a lower share of the population, a comparative delineation of metropolitan areas at the level of municipalities and at the level of counties would be useful. This is, however, beyond the scope of the present paper.

\section{Robustness}

The regression model in the first step and the delineation rules in the second step rest on several assumptions and ex ante choices. This section investigates the robustness of the delineation results to variations of these assumptions and choices, using the illustrative delineation presented in Section 3 as an example and a reference. These robustness tests will not just assess whether or not the delineation results are sensitive to the assumptions and ex ante choices. Any approach that, like the approaches for delineating metropolitan areas, forces a population of interdependent units into just two classes of units is, by nature, sensitive to variations in the definition of the classes and the rules for assigning the units to these classes. As the commuting-based delineations, the land-price-based delineation proposed here will consequently be sensitive to a variation of the assumptions and ex ante choices. See Karlsson and Olsson (2006) for a discussion of the robustness of commuting-based delineations. The robustness tests will also investigate $w h y$ the delineation results are sensitive to the assumptions and ex ante choices. They may thereby help understand how the delineation approach works, and which assumptions or choices need to be investigated in more detail in future research to reduce the sensitivity of the delineation results as far as possible.

Table 2 reports the main results of the robustness tests, along with those of the baseline delineation presented above. The upper panel of Table 2 reports, for each test as well as for the baseline delineation, summary statistics for the results of the second step of the procedure, namely the number of metropolitan areas and their counties, and three "overlap" indicators. The overlap indicators are the share of metropolitan areas in the baseline delineation that are metropolitan areas in the test delineation as well ("\% same metro areas"), the share of metropolitan counties in the baseline delineation that are metropolitan counties in the test delineation as well ("\% counties in metro areas"), and the share of metropolitan counties in the baseline delineation that are members of the same metropolitan area in the test delineation ("\% counties in same

\footnotetext{
${ }^{12}$ Reducing the significance threshold from $€ 20$ to $€ 0$ in the second step of the delineation does not change this general picture fundamentally.
} 
metro area"). The lower panel of Table 2 reports the correlations (Pearson coefficients) between the baseline and the test delineations for the estimated rural land prices and urban land prices. It also reports, similar to Table 1, the numbers and types of the parameters in the delineations.

First, the delineation results can be expected to be sensitive to the choice of the significance threshold in the second step of the delineation procedure. Since the standard deviations of the urban land prices estimated in Section 3 are unknown, all counties with an estimated urban land price of $€ 20$ or more are considered parts of metropolitan areas. The robustness tests indicate that the number of counties in metropolitan areas changes significantly if the significance threshold is reduced to $€ 10$, or increased to $€ 30$ (Table 2 , columns i.a and i.b). It increases by 9 percent (from 167 in the baseline delineation to 182) if the significance threshold is reduced by 50 percent, and decreases by 6 percent (to 157) if the significance threshold is increased by 50 percent. ${ }^{13}$ This underscores the need for an estimator of the standard deviations of the predicted urban land prices that allows subjecting the significance of the estimates to more widely accepted significance levels.

Second, the delineation results may be sensitive to the choice of the set of candidate centers from which the selection procedure draws the metropolitan centers. The delineation results do, in fact, change significantly, if the 91 city-counties in West Germany (see Section 3) are chosen to be the candidate centers instead of the 112 centers of the labor market areas (Table 2, column ii). Although the set of candidate centers is smaller, the delineation procedure identifies more and, on aggregate, larger metropolitan areas. Of the 43 metropolitan areas identified in the test delineation based on the 91 city-counties, 32 (88 percent of 40) are also identified in the baseline delineation based on the 112 centers of labor market areas. Five of the remaining 11 metropolitan areas are considered rural areas in the baseline delineation, while six are merged into polycentric metropolitan areas in the baseline delineation. The total number of metropolitan counties, 192, is significantly higher than in the baseline delineation mainly because some of the metropolitan areas identified in both delineations are larger in the test than in the baseline delineation. ${ }^{14}$ The indicators for the results of the first-step regression in the lower panel of Table 2 show that the test model fits the data better, according to the adjusted $R^{2}$, predicts the rural land price to be lower (€55 instead of $€ 64$ ), and identifies

${ }^{13}$ The number of metropolitan areas and the assignment of counties to specific metropolitan areas do not change too much, by contrast. The number of metropolitan areas decreases or increases by just one because one more or one less metropolitan area is merged with another metropolitan area. The assignment of the counties to the metropolitan areas changes accordingly, which explains why only 92 percent or 93 percent of the metropolitan counties are in the same metropolitan area in the baseline and the test delineations.

${ }^{14}$ The share of larger metropolitan areas (population>330,000) in the total West German population is 65 percent, which is still lower than the population share of the larger European FURs (70 percent see Section 3). 


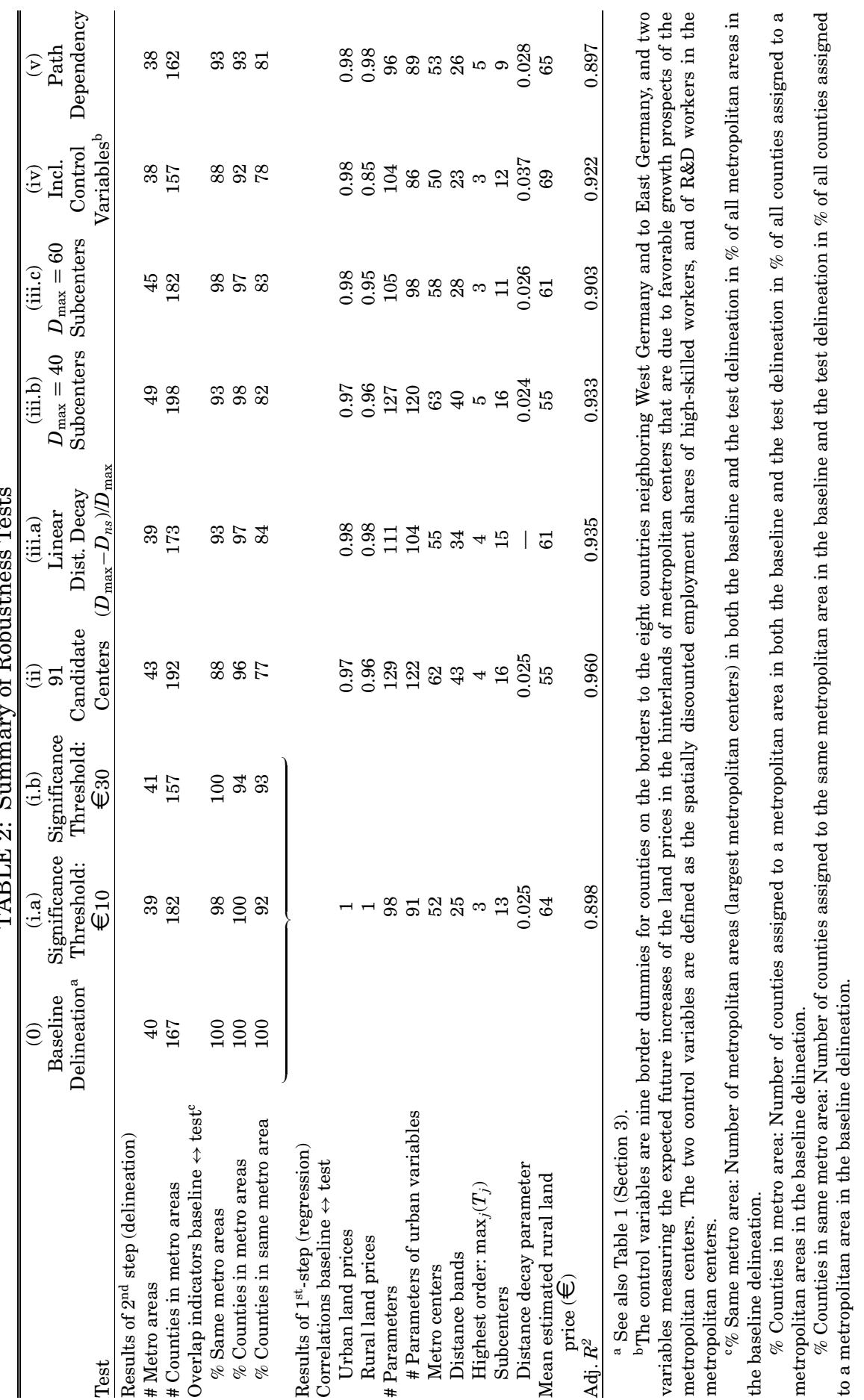

(C) Blackwell Publishing, Inc. 2008. 
significantly more of all three types of metropolitan variables (metropolitan centers, distance bands, subcenters).

To understand why the test delineation identifies more and, on aggregate, larger metropolitan areas than the baseline delineation, it is important to know that the city-counties are spatially more clustered in densely populated areas than the centers of labor market areas. This implies that, on the one hand, the selection procedure in the first-step regression has more opportunities for placing center dummies in densely populated areas-and for adding another distance band here and there-in the test delineation. In the baseline delineation, the selection procedure instead has to place subcenters, whose land price gradients are subject to stronger restrictions. On the other hand, the stronger clustering of city-counties implies that the selection procedure has fewer opportunities for placing center dummies in sparsely populated areas in the test delineation. This appears to be of little use in the present case because there are, apparently, not too many metropolitan centers among the centers of the labor market areas in West Germany that are not city-counties. The lesson to be drawn for future research from this test is that the apparent sensitivity of the results to the choice of the candidate metropolitan centers may actually be a consequence of their sensitivity to the choice of the restrictions imposed on the land price gradients of subcenters. To improve the "fine tuning" of the model, the restrictions imposed on the land price gradients of the subcenters should be relaxed as far as possible.

To investigate the sensitivity of the delineation procedure to the restrictions imposed on the land price gradients of the subcenters in some more detail, the third set of robustness tests focuses on the functional form of these gradients. The test reported in column (iii.a) employs a linear rather than an inverse exponential distance decay function, and the tests reported in columns (iii.b) and (iii.c) employ different distance cutoffs $\left(D_{\max }\right)$. The results of these tests indicate that the delineation tends to be more sensitive to the choice of the distance cutoff than to the choice of the functional form of the land price gradients of subcenters: Setting the spatial discounting factor, $w_{n s}$, equal to $\left(50-D_{n s}\right) / 50$ rather than to the inverse exponential function given in equation (4) does not affect the delineation results significantly (column iii.a). By contrast, reducing the distance cutoff from $50 \mathrm{~km}$ in the baseline model to $40 \mathrm{~km}$ (column iii.b), or extending it to $60 \mathrm{~km}$ (column iii.c), affects the delineation results significantly and in a fairly complex way. While the number of subcenters identified by the selection procedure in the first step (see lower panel of Table 2) decreases continuously with an increasing cutoff, as could be expected, the numbers of metropolitan areas and counties in these metropolitan areas are higher for both the $40 \mathrm{~km}$ and $60 \mathrm{~km}$ cutoffs than for the $50 \mathrm{~km}$ cutoff. The same is true for the number of metropolitan centers and distance bands identified by the selection procedure. This puzzling result may be due to the restriction that the distance decay parameters are the same for all subcenters. This one-size-fits-all restriction can be expected to introduce complex interdependencies between all metropolitan areas that are not circularly symmetric. 
Fourth, the results presented in Section 3 may be biased because interactions across the national border are not taken into account. In addition, the land prices at the metropolitan fringes may be affected significantly by expected future changes of the land rents in prosperous metropolitan areas (Capozza and Helsley, 1990). These expectations are considered a dynamic externality of urban agglomeration in the present paper that should be taken into account when delineating today's metropolitan areas. It may, still, be interesting to know to what extent they actually affect the delineation. The test delineation in column (v) of Table 2 indicates that the delineation results do not change dramatically if border effects and the effects of expected changes of the land rents are taken into account. ${ }^{15}$ Counties on the borders to the former Socialist countries (including East Germany) tend to have somewhat lower, those on the borders to western European countries somewhat higher, land prices, ceteris paribus. Expected future changes in the land rents are found to exhibit little influence on the land prices. The estimated effects of the human-capital intensity of a metropolitan center are virtually zero; those of the R\&D intensity implausibly negative.

Finally, the variable-selection procedure may be subject to path dependency. Although every variable in the model is tested in each iteration to determine whether it may be excluded, there may be variables or combinations of variables that are particularly influential in the sense that they, once they have been added to the model, direct the subsequent iterations towards a local rather than the global maximum of the objective function. Sensitivity to path dependency is tested by repeatedly removing or adding randomly variables in the course of the iterations. In most, though not all, cases the procedure corrects the random interferences of the selection process in the following iteration. It reintroduces the variable that was removed randomly, or removes the variable that was added randomly. Still, the test delineation in column (vi) of Table 2 indicates that the delineation results are not invariant to path dependency. The selection procedure tends to become more sensitive to path dependency towards higher iterations, as the set of options for adding or removing variables becomes larger and the differences between these options in terms of the objective function (adjusted $R^{2}$ ) become smaller.

\section{CONCLUSION}

This paper proposes a new approach for delineating metropolitan areas. While the standard approaches use commuting intensities as an indicator of

\footnotetext{
${ }^{15}$ The border effects are controlled for by nine border dummies that are one for counties on the borders to the eight countries neighboring West Germany, or to East Germany. The effects of favorable growth prospects of the metropolitan centers on the land prices at the metropolitan fringes are controlled for by two variables: the spatially discounted employment shares of highskilled workers in the metropolitan centers, and the spatially discounted employment shares of R\&D workers in the metropolitan centers. Both variables assume, ceteris paribus, higher values for counties in the neighborhood of more innovative metropolitan centers. The regression results, which are not reported here in detail, are available from the author upon request.
} 
economic integration between metropolitan centers and their hinterlands, the present paper uses the fraction of land prices attributable to economies of urban agglomeration as an indicator. This fraction, labeled "urban land price" for short, reflects, in addition to commuting, a variety of economic interactions and interdependencies, including externalities between firms. While this approach is formally quite similar to the traditional, commuting-based delineation approaches, it differs conceptually in three respects: it estimates the urban land prices econometrically by adapting the concept of land price gradients from the economic theory of cities, takes subcenters of metropolitan areas explicitly into account, and identifies the centers and subcenters of metropolitan areas endogenously.

Using this approach to delineate metropolitan areas in West Germany demonstrates, first, that this approach tends to delineate fewer and larger metropolitan areas in densely populated parts of the country than commutingbased delineation approaches. This may be due to the fact that the approach accounts for interactions between firms in different centers or subcenters that exceed the usual commuting distances. Second, it demonstrates that this approach tends to delineate smaller metropolitan areas in sparsely populated parts of the country. This is probably due to the fact that the approach assigns a lower weight to the urbanized municipalities in counties at the metropolitan fringes that comprise both urbanized and rural municipalities. On aggregate, the population share in metropolitan areas delineated by means of land prices is found to be smaller than that in metropolitan areas delineated by means of commuting intensities. For assessing the relative merits and drawbacks of the land price and the commuting-based approaches in different environments, more detailed comparative studies and simulations are warranted, however.

The main purpose of this paper is to introduce the basic approach to delineating metropolitan areas by means of land prices. This approach still rests on several simplifying assumptions that may, and should be relaxed as far as possible in the future. One of these assumptions is that the land price gradients of all subcenters are assumed to be of the same shape. Future research should explore opportunities for allowing the land price gradients of subcenters to adjust more flexibly to the local specificities of the subcenters. Another simplifying assumption is that the statistical significance of the urban land prices cannot be determined by means of simulations. Future research should explore opportunities for estimating the standard deviations urban land prices by, for example, employing the bootstrap or other simulation methods.

\section{REFERENCES}

Abdel-Rahman, Hesham M. and Alex Anas. 2004. "Theories of Systems of Cities," in J. Vernon Henderson and Jacques-Francois Thisse (eds.), Handbook of Urban and Regional Economics, Volume 4. Amsterdam: North Holland.

Abel, Wilhelm. 1955. "Schichten und Zonen europäischer Agrarverfassung," Zeitschrift für Agrargeschichte und Agrarsoziologie, 3(1), 1-19. 
Anas, Alex, Richard J. Arnott, and Kenneth A. Small. 1998. "Urban Spatial Structure," Journal of Economic Literature, 36(3), 1426-1464.

Anas, Alex, and Kai Xiong. 2005. "The Formation and Growth of Specialized Cities: Efficiency Without Developers or Malthusian Traps," Regional Science and Urban Economics, 35(4), 445470.

Anselin, Luc, Attila Varga, and Zoltan J. Acs. 1997. "Local Geographic Spillovers between University Research and High Technology Innovations," Journal of Urban Economics, 42(3), 422-448.

Bode, Eckhardt. 2004. "The Spatial Pattern of Localized R\&D Spillovers: An Empirical Investigation for Germany," Journal of Economic Geography, 4(1), 43-64.

Brakman, Steven, Harry Garretsen, and Marc Schramm. 2004. "The Spatial Distribution of Wages: Estimating the Helpman-Hansen Model for Germany," Journal of Regional Science, 44(3), 437466.

Capozza, Dennis R. and Robert W. Helsley. 1990. "The Stochastic City," Journal of Urban Economics, 28(2), 187-203.

Cheshire, Paul C. and Dennis G. Hay. 1989. Urban Problems in Western Europe: An Economic Analysis. London: Unwin Hyman.

Cohen, Jeffrey P. and Catherine Morrison Paul. 2007. "The Impacts of Transportation Infrastructure on Property Values: A Higher-order Spatial Econometrics Approach,” Journal of Regional Science, 47(3), 457-478.

Combes, Pierre-Philippe, and Henry G. Overman. 2004. "The Spatial Distribution of Economic Activities in the European Union," in J. Vernon Henderson and Jacques-Francois Thisse (eds.), Handbook of Urban and Regional Economics, Volume 4. Amsterdam: North Holland.

Dohse, Dirk, Christiane Krieger-Boden, Birgit Sander, and Rüdiger Soltwedel. 2002. "Vom Mangel zum Überfluss - der ostdeutsche Wohnungsmarkt in der Subventionsfalle." Kiel Discussion Papers 395. Kiel: Kiel Institute for the World Economy.

Duranton, Gilles. 2006. "Human Capital Externalities in Cities: Identification and Policy Issues," in Richard J. Arnott and Daniel P. McMillen (eds.), A Companion to Urban Economics. Malden: Blackwell.

Duranton, Gilles, and Diego Puga. 2004. "Micro-foundations of Agglomeration Economies," in J. Vernon Henderson and Jacques-Francois Thisse (eds.), Handbook of Urban and Regional Economics, Volume 4. Amsterdam: North Holland.

Eckey, Hans-Friedrich, Reinhold Kosfeld, and Matthias Türck. 2006. "Abgrenzung deutscher Arbeitsmarktregionen," Raumforschung und Raumordnung, 64(4), 299-309.

Fujita, Masahisa. 1989. Urban Economic Theory. Cambridge: Cambridge University Press.

Fujita, Masahisa, and Jacques-Francois Thisse. 2002. Economics of Agglomeration. Cambridge: Cambridge Univ. Press.

Hanson, Gordon H. 2005. "Market Potential, Increasing Returns, and Geographic Concentration," Journal of International Economics, 67(1), 1-24.

Karlsson, Charlie, and Michael Olsson. 2006. "The Identification of Functional Regions: Theory, Methods, and Applications," Annals of Regional Science, 40(1), 1-18.

Lucas, Robert E. and Esteban Rossi-Hansberg. 2002. "On the Internal Structure of Cities," Econometrica, 70(4), 1445-1476.

McMillen, Daniel P. and Stefani C. Smith. 2003. "The Number of Subcenters in Large Urban Areas," Journal of Urban Economics, 53(3), 321-338.

Mills, Edwin S. and Jee Peng Tan. 1980. "A Comparison of Urban Population Density Functions in Developed and Developing Countries," Urban Studies, 17(3), 313-321.

Mion, Giordano. 2004. "Spatial Externalities and Empirical Analysis: The Case of Italy," Journal of Urban Economics, 56(1), 97-118.

Mori, Tomoya, Koji Nishikimi, and Tony E. Smith. 2005. "On the Empirical Identification of Industrial Agglomerations and their Spatial Coordination." Kyoto: Kyoto University.

Mori, Tomoya, and Tony E. Smith. 2006. "A Probabilistic Modeling Approach to the Detection of Industrial Agglomerations.” Kyoto: Kyoto University. 
Office of Management and Budget (OMB). 2000. "Standards for Defining Metropolitan and Micropolitan Statistical Areas," Federal Register, 65(No. 249), December 27, 2000, pp. 82228-82238.

Papageorgiou, Yorgos Y. and David Pines. 1989. "The Exponential Density Function: First Principles, Comparative Statics, and Empirical Evidence," Journal of Urban Economics, 26(2), 264-268.

Rehdanz, Katrin, and David Maddison. 2004. "The Amenity Value of Climate to German Households." Working Paper FNU-39. Hamburg: Hamburg University.

Roback, Jennifer. 1982. "Wages, Rents, and the Quality of Life," Journal of Political Economy, 90(6), 1257-1278.

Rosenthal, Stuart S. and William C. Strange. 2003. "Geography, Industrial Organization, and Agglomeration," Review of Economics and Statistics, 85(2), 377-393.

Rosenthal, Stuart S. and William C. Strange. 2004. "Evidence on the Nature and Sources of Agglomeration Economies," in J. Vernon Henderson and Jacques-Francois Thisse (eds.), Handbook of Urban and Regional Economics, Volume 4. Amsterdam: North Holland.

Rosenthal, Stuart S. and William C. Strange. 2006. "The Attenuation of Human Capital Spillovers." Toronto: University of Toronto.

Rossi-Hansberg, Esteban, Pierre-Daniel Sarte, and Raymond Owens, III. 2006. "Firm Fragmentation and Urban Patterns." Princeton: Princeton University.

Rouwendal, Jan, and Piet Rietveld. 1994. "Changes in Commuting Distances of Dutch Households," Urban Studies, 31(9), 1545-1557.

US Census Bureau (USCB). 2006. "Metropolitan and Micropolitan Statistical Areas: What are Metropolitan and Micropolitan Statistical Areas?" Washington, D.C.: http://www.census. gov/population/www/estimates/metroarea.html (August 18, 2006). 


\section{APPENDIX}

TABLE A1: Regression Results For equation (1)

\begin{tabular}{|c|c|c|c|c|c|}
\hline \multirow{2}{*}{\multicolumn{3}{|c|}{$\begin{array}{l}\text { Variable Parameter } \\
\text { Determinants of Urban Land Prices }\end{array}$}} & \multirow{2}{*}{\multicolumn{2}{|c|}{ Variable }} & \multirow[t]{2}{*}{ Parameter } \\
\hline & & & & & \\
\hline Center & Kiel & 124.71 & Center & Freiburg im Breisgau & 209.61 \\
\hline Center & Lübeck & 42.32 & $1^{\text {st }}$ ring & Freiburg im Breisgau & 107.57 \\
\hline Center & Hamburg & 557.82 & Center & Reutlingen & 70.38 \\
\hline $1^{\text {st }}$ ring & Hamburg & 448.84 & Center & Ulm & 92.91 \\
\hline Center & Braunschweig & 72.13 & Center & Ingolstadt & 212.83 \\
\hline Center & Wolfsburg & 44.36 & Center & München & 575.02 \\
\hline Center & Region Hannover & 89.42 & $1^{\text {st }}$ ring & München & 128.40 \\
\hline Center & Oldenburg & 64.25 & $2^{\text {nd }}$ ring & München & 150.03 \\
\hline Center & Osnabrück & 81.07 & Center & Rosenheim & 132.32 \\
\hline Center & Bremen & 81.68 & Center & Garmisch-Partenkirchen & 165.75 \\
\hline $1^{\text {st }}$ ring & Bremen & 70.82 & $1^{\text {st }}$ ring & Garmisch-Partenkirchen & 1480.42 \\
\hline Center & Düsseldorf & 162.79 & Center & Landshut & 211.22 \\
\hline $1^{\text {st }}$ ring & Düsseldorf & 22.94 & Center & Passau & 57.26 \\
\hline $2^{\text {nd }}$ ring & Düsseldorf & 76.89 & Center & Straubing & 76.98 \\
\hline $3^{\text {rd }}$ ring & Düsseldorf & 1.02 & Center & Amberg & 66.72 \\
\hline Center & Essen & 80.20 & Center & Regensburg & 122.66 \\
\hline Center & Krefeld & 101.53 & Center & Weiden i.d. Oberpfalz & 88.06 \\
\hline Center & Aachen & 108.53 & Center & Bamberg & 103.51 \\
\hline Center & Köln & 181.60 & Center & Bayreuth & 134.71 \\
\hline Center & Münster & 131.31 & Center & Ansbach & 48.77 \\
\hline $1^{\text {st }}$ ring & Münster & 100.91 & Center & Nürnberg & 278.00 \\
\hline Center & Bielefeld & 102.06 & $1^{\text {st }}$ ring & Nürnberg & 160.47 \\
\hline $1^{\text {st }}$ ring & Bielefeld & 94.02 & Center & Aschaffenburg & 227.83 \\
\hline Center & Paderborn & 48.97 & $1^{\text {st }}$ ring & Aschaffenburg & 98.23 \\
\hline Center & Dortmund & 68.60 & Center & Schweinfurt & 83.20 \\
\hline Center & Darmstadt & 271.37 & Center & Würzburg & 223.54 \\
\hline Center & Frankfurt am Main & 556.21 & $1^{\text {st }}$ ring & Würzburg & 77.64 \\
\hline $1^{\text {st }}$ ring & Frankfurt am Main & 225.75 & Center & Augsburg & 211.88 \\
\hline $2^{\text {nd }}$ ring & Frankfurt am Main & 103.64 & $1^{\text {st }}$ ring & Augsburg & 116.94 \\
\hline Center & Wiesbaden & 338.76 & Center & Kempten & 122.44 \\
\hline $1^{\text {st }}$ ring & Wiesbaden & 138.94 & Center & Memmingen & 111.91 \\
\hline $2^{\text {nd }}$ ring & Wiesbaden & 116.28 & Subcenter & Oberhausen & 1.47 \\
\hline Center & Koblenz & 121.34 & Subcenter & Viersen & 3.86 \\
\hline Center & Trier & 86.59 & Subcenter & Erftkreis & 2.42 \\
\hline Center & Kaiserslautern & 65.10 & Subcenter & Rheinisch-Bergischer Kreis & 7.34 \\
\hline Center & Mainz & 157.88 & Subcenter & Coesfeld & 1.59 \\
\hline Center & Stuttgart & 608.96 & Subcenter & Bochum & 247.51 \\
\hline $1^{\text {st }}$ ring & Stuttgart & 422.36 & Subcenter & Darmstadt-Dieburg & 1.13 \\
\hline $2^{\text {nd }}$ ring & Stuttgart & 109.63 & Subcenter & Hochtaunuskreis & 0.41 \\
\hline $3^{\text {rd }}$ ring & Stuttgart & 129.21 & Subcenter & Speyer & 1.24 \\
\hline Center & Heilbronn & 146.77 & Subcenter & Heilbronn (LK) & 0.91 \\
\hline Center & Karlsruhe & 167.71 & Subcenter & München (LK) & 2.70 \\
\hline $1^{\text {st }}$ ring & Karlsruhe & 54.24 & Subcenter & Starnberg & 0.83 \\
\hline $2^{\text {nd }}$ ring & Karlsruhe & 111.23 & Subcenter & Erlangen & 0.34 \\
\hline Center & Mannheim & 182.20 & & & \\
\hline $1^{\text {st }}$ ring & Mannheim & 204.03 & Distance $\mathrm{d}$ & ay parameter & 0.025 \\
\hline
\end{tabular}


TABLE A1: (Continued)

\begin{tabular}{lrlr}
\hline Variable & Parameter & \multicolumn{1}{c}{ Variable } & Parameter \\
\hline $\begin{array}{l}\text { Determinants of rural } \\
\text { components of land prices }\end{array}$ & -154.59 & Descriptive statistics & \\
Intercept & 8.63 & Sum. $R^{2}$ & 0.898 \\
INHERIT & 43.84 & Sum of squared residuals $(1,000)$ & 351 \\
MOUNTAIN & 0.88 & Observations & 4,902 \\
SOIL & 0.00 & Iterations selection procedure & 326 \\
SOILSQ & 0.20 & & 94 \\
RELIEF_INTENS & 53.65 & & \\
SUNSHINE & & & \\
\hline
\end{tabular}

TABLE A2: Metropolitan Areas and Their Counties In West Germany: Results of the Illustrative Delineation in Section $3^{\text {a }}$

\begin{tabular}{|c|c|c|c|c|c|c|c|}
\hline $\begin{array}{l}\text { Metro } \\
\text { ID }\end{array}$ & $\begin{array}{c}\text { County } \\
\text { ID }\end{array}$ & $\begin{array}{l}\text { Metro/ } \\
\text { County } \\
\text { Name }\end{array}$ & $\begin{array}{l}\text { Urban } \\
\text { Land } \\
\text { Price }\end{array}$ & $\begin{array}{l}\text { Metro } \\
\text { ID }\end{array}$ & $\begin{array}{c}\text { County } \\
\text { ID }\end{array}$ & $\begin{array}{c}\text { Metro/ } \\
\text { County } \\
\text { Name }\end{array}$ & $\begin{array}{l}\text { Urban } \\
\text { Land } \\
\text { Price } \\
\end{array}$ \\
\hline 1 & 1002 & Kiel & 125 & 10 & & Rhine-Ruhr (cont'd) & \\
\hline 2 & 1003 & Lübeck & 42 & & 5382 & Rhein-Sieg-Kreis & 47 \\
\hline \multirow[t]{5}{*}{3} & & Hamburg & & & 5512 & Bottrop & 109 \\
\hline & 1056 & Pinneberg & 92 & & 5513 & Gelsenkirchen & 123 \\
\hline & 2000 & Hamburg & 558 & & 5562 & Recklinghausen & 127 \\
\hline & 3353 & Harburg & 62 & & 5911 & Bochum & 156 \\
\hline & 3359 & Stade & 28 & & 5913 & Dortmund & 174 \\
\hline 4 & 3101 & Braunschweig & 72 & & 5914 & Hagen & 59 \\
\hline 5 & 3103 & Wolfsburg & 44 & & 5915 & Hamm & 43 \\
\hline 6 & 3241 & Region Hannover & 89 & & 5916 & Herne & 144 \\
\hline 7 & 3403 & Oldenburg & 64 & & 5954 & Ennepe-Ruhr-Kreis & 108 \\
\hline 8 & 3404 & Osnabrück & 81 & & 5962 & Märkischer Kreis & 46 \\
\hline \multirow[t]{4}{*}{9} & & Bremen & & & 5974 & Soest & 39 \\
\hline & 3356 & Osterholz & 34 & & 5978 & Unna & 89 \\
\hline & 3401 & Delmenhorst & 71 & 11 & 5313 & Aachen & 123 \\
\hline & 4011 & Bremen & 82 & 12 & & Münster & \\
\hline \multirow[t]{24}{*}{10} & & Rhine-Ruhr & & & 5515 & Münster & 155 \\
\hline & 5111 & Düsseldorf & 266 & & 5554 & Borken & 45 \\
\hline & 5112 & Duisburg & 165 & & 5558 & Coesfeld & 85 \\
\hline & 5113 & Essen & 235 & & 5566 & Steinfurt & 36 \\
\hline & 5114 & Krefeld & 212 & 13 & 5570 & Warendorf & 30 \\
\hline & 5116 & Mönchengladbach & 127 & & & Bielefeld & \\
\hline & 5117 & Mülheim/Ruhr & 148 & & 5711 & Bielefeld & 102 \\
\hline & 5119 & Oberhausen & 156 & & 5754 & Gütersloh & 41 \\
\hline & 5120 & Remscheid & 134 & & 5758 & Herford & 52 \\
\hline & 5122 & Solingen & 162 & & 5774 & Paderborn & 49 \\
\hline & 5124 & Wuppertal & 109 & 14 & & Rhine-Main & \\
\hline & 5158 & Mettmann & 141 & & 6411 & Darmstadt & 379 \\
\hline & 5162 & Neuss & 142 & & 6412 & Frankfurt am Main & 714 \\
\hline & 5166 & Viersen & 115 & & 6413 & Offenbach am Main & 310 \\
\hline & 5170 & Wesel & 73 & & 6414 & Wiesbaden & 436 \\
\hline & 5314 & Bonn & 52 & & 6432 & Darmstadt-Dieburg & 155 \\
\hline & 5315 & Köln & 279 & & 6433 & Groß-Gerau & 197 \\
\hline & 5316 & Leverkusen & 179 & & 6434 & Hochtaunuskreis & 331 \\
\hline & 5358 & Düren & 23 & & 6435 & Main-Kinzig-Kreis & 105 \\
\hline & 5362 & Erftkreis & 121 & & 6436 & Main-Taunus-Kreis & 354 \\
\hline & 5370 & Heinsberg & 44 & & 6438 & Offenbach (LK) & 301 \\
\hline & 5374 & Oberbergischer Kreis & 37 & & 6439 & Rüdesheim & 142 \\
\hline & 5378 & Rheinisch-Berg. Kreis & 143 & & 6440 & Wetteraukreis & 107 \\
\hline & & & & & 6531 & Gießen & 34 \\
\hline
\end{tabular}

(C) Blackwell Publishing, Inc. 2008. 
TABLE A2: (Continued)

\begin{tabular}{|c|c|c|c|c|c|c|c|}
\hline $\begin{array}{l}\text { Metro } \\
\text { ID }\end{array}$ & $\begin{array}{c}\text { County } \\
\text { ID }\end{array}$ & $\begin{array}{c}\text { Metro/ } \\
\text { County } \\
\text { Name }\end{array}$ & $\begin{array}{l}\text { Urban } \\
\text { Land } \\
\text { Price }\end{array}$ & $\begin{array}{c}\text { Metro } \\
\text { ID }\end{array}$ & $\begin{array}{c}\text { County } \\
\text { ID }\end{array}$ & $\begin{array}{c}\text { Metro/ } \\
\text { County } \\
\text { Name }\end{array}$ & $\begin{array}{l}\text { Urban } \\
\text { Land } \\
\text { Price }\end{array}$ \\
\hline \multirow[t]{6}{*}{14} & & Rhine-Main (cont'd) & & 24 & & München (cont'd) & \\
\hline & 6532 & Lahn-Dill-Kreis & 36 & & 9175 & Ebersberg & 217 \\
\hline & 6533 & Limburg-Weilburg & 22 & & 9177 & Erding & 166 \\
\hline & 7141 & Rhein-Lahn-Kreis & 24 & & 9178 & Freising & 195 \\
\hline & 7315 & Mainz & 336 & & 9179 & Fürstenfeldbruck & 268 \\
\hline & 7339 & Mainz-Bingen & 117 & & 9181 & Landsberg am Lech & 26 \\
\hline 15 & 7111 & Koblenz & 121 & & 9182 & Miesbach & 136 \\
\hline 16 & 7211 & Trier & 87 & & 9184 & München (LK) & 509 \\
\hline 17 & 7312 & Kaiserslautern & 65 & & 9186 & Pfaffenhofen a.d. Ilm & 122 \\
\hline \multirow[t]{15}{*}{18} & & Stuttgart & & & 9187 & Rosenheim (LK) & 125 \\
\hline & 8111 & Stuttgart & 609 & & 9188 & Starnberg & 298 \\
\hline & 8115 & Böblingen & 259 & 25 & & Garmisch-Partenkirchen & \\
\hline & 8116 & Esslingen & 257 & & 9173 & Bad Tölz-Wolfratshausen & 125 \\
\hline & 8117 & Göppingen & 46 & & 9180 & Garmisch-Partenkirchen & 166 \\
\hline & 8118 & Ludwigsburg & 266 & & 9190 & Weilheim-Schongau & 73 \\
\hline & 8119 & Rems-Murr-Kreis & 170 & & 9777 & Ostallgäu & 62 \\
\hline & 8121 & Heilbronn & 214 & 26 & 9261 & Landshut & 211 \\
\hline & 8125 & Heilbronn (LK) & 111 & 27 & 9262 & Passau & 57 \\
\hline & 8225 & Neckar-Odenwald-Kreis & 21 & 28 & 9263 & Straubing & 77 \\
\hline & 8231 & Pforzheim & 190 & 29 & 9361 & Amberg & 67 \\
\hline & 8235 & Calw & 55 & 30 & 9362 & Regensburg & 123 \\
\hline & 8236 & Enzkreis & 122 & 31 & 9363 & Weiden i.d. Oberpfalz & 88 \\
\hline & 8415 & Reutlingen & 115 & 32 & 9462 & Bayreuth & 135 \\
\hline & 8416 & Tübingen & 72 & 33 & 9561 & Ansbach & 49 \\
\hline \multirow[t]{7}{*}{19} & & Karlsruhe & & 34 & & Nürnberg & \\
\hline & 7313 & Landau & 116 & & 9373 & Neumarkt i.d. Oberpfalz & 21 \\
\hline & 7334 & Germersheim & 105 & & 9461 & Bamberg & 127 \\
\hline & 7337 & Südliche Weinstraße & 35 & & 9471 & Bamberg (LK) & 25 \\
\hline & 8212 & Karlsruhe & 201 & & 9474 & Forchheim & 33 \\
\hline & 8215 & Karlsruhe (LK) & 100 & & 9562 & Erlangen & 191 \\
\hline & 8216 & Rastatt & 44 & & 9563 & Fürth & 197 \\
\hline \multirow[t]{13}{*}{20} & & Mannheim & & & 9564 & Nürnberg & 310 \\
\hline & 6431 & Bergstrasse & 127 & & 9565 & Schwabach & 185 \\
\hline & 7311 & Frankenthal & 254 & & 9572 & Erlangen-Höchstadt & 82 \\
\hline & 7314 & Ludwigshafen & 249 & & 9573 & Fürth (LK) & 149 \\
\hline & 7316 & Neustadt a.d.W. & 49 & & 9574 & Nürnberger Land & 73 \\
\hline & 7318 & Speyer & 191 & & 9575 & Neustadt/A.-Bad Windsh. & 20 \\
\hline & 7319 & Worms & 137 & & 9576 & Roth & 63 \\
\hline & 7331 & Alzey-Worms & 42 & 35 & & Aschaffenburg & \\
\hline & 7332 & Bad Dürkheim & 63 & & 6437 & Odenwaldkreis & 33 \\
\hline & 7338 & Ludwigshafen (LK) & 237 & & 9661 & Aschaffenburg & 256 \\
\hline & 8221 & Heidelberg & 233 & & 9671 & Aschaffenburg (LK) & 119 \\
\hline & 8222 & Mannheim & 230 & & 9676 & Miltenberg & 31 \\
\hline & 8226 & Rhein-Neckar-Kreis & 100 & 36 & 9662 & Schweinfurt & 83 \\
\hline \multirow[t]{4}{*}{21} & & Freiburg & & 37 & & Würzburg & \\
\hline & 8311 & Freiburg im Breisgau & 210 & & 9663 & Würzburg & 224 \\
\hline & 8315 & Breisgau-Hochschw. & 56 & & 9679 & Würzburg (LK) & 63 \\
\hline & 8316 & Emmendingen & 38 & 38 & & Augsburg & \\
\hline 22 & 8421 & Ulm & 93 & & 9761 & Augsburg & 212 \\
\hline 23 & 9161 & Ingolstadt & 213 & & 9771 & Aichach-Friedberg & 76 \\
\hline \multirow[t]{4}{*}{24} & & München & & & 9772 & Augsburg (LK) & 55 \\
\hline & 9162 & München & 874 & 39 & 9763 & Kempten & 122 \\
\hline & 9163 & Rosenheim & 241 & 40 & 9764 & Memmingen & 112 \\
\hline & 9174 & Dachau & 306 & & & & \\
\hline
\end{tabular}

asee Section 3 for the details of the estimation of the predicted urban land prices and the delineation of the metropolitan areas.

(C) Blackwell Publishing, Inc. 2008. 

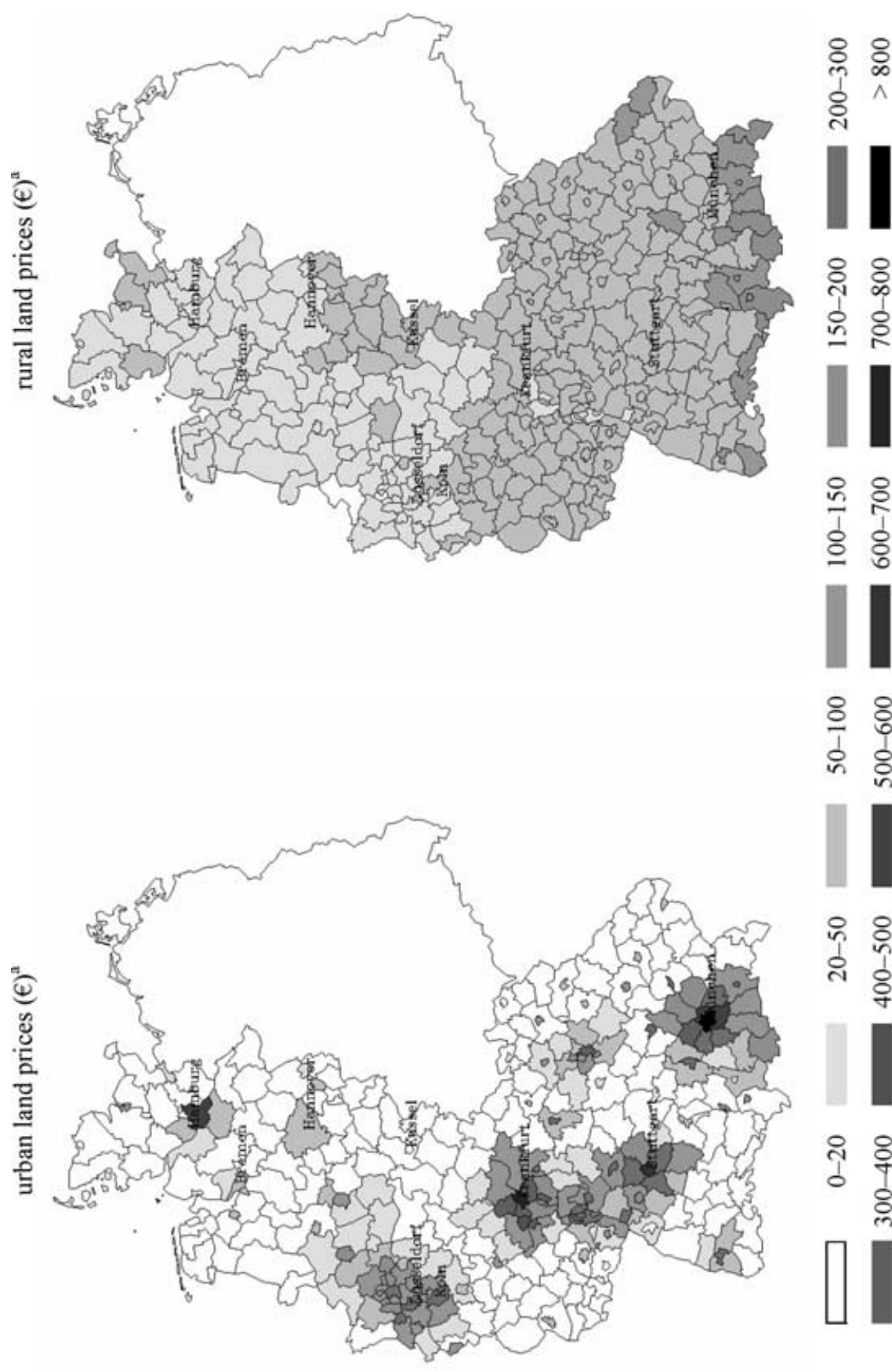

$\circ$
1
1
8
8

(1)

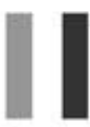

우

응

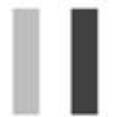

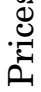

$\begin{array}{ll}\circ & 8 \\ 1 & 0 \\ 0 & 1 \\ & 0\end{array}$

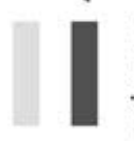

용 \&

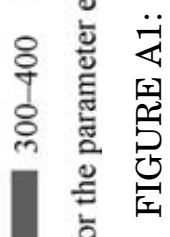

C Blackwell Publishing, Inc. 2008. 